OPEN ACCESS

Edited by:

Vikas Prasad,

Universitätsklinikum Ulm, Germany

Reviewed by:

Francesco Ceci,

Università di Torino,

Italy

Murat Fani Bozkurt,

Hacettepe University, Turkey

${ }^{*}$ Correspondence:

Rathan M. Subramaniam

rathan.subramaniam@otago.ac.nz

Specialty section:

This article was submitted to

Cancer Imaging and

Image-directed Interventions,

a section of the journal

Frontiers in Oncology

Received: 15 August 2021

Accepted: 18 October 2021

Published: 11 November 2021

Citation:

Kuyumcu S, Sanli Y and Subramaniam RM (2021) FibroblastActivated Protein Inhibitor PET/CT: Cancer Diagnosis and Management.

Front. Oncol. 11:758958.

doi: 10.3389/fonc.2021.758958

\section{Fibroblast-Activated Protein Inhibitor PET/CT: Cancer Diagnosis and Management}

\author{
Serkan Kuyumcu ${ }^{1}$, Yasemin Sanli ${ }^{1}$ and Rathan M. Subramaniam ${ }^{2,3 *}$ \\ ${ }^{1}$ Department of Nuclear Medicine, Istanbul Faculty of Medicine, Istanbul University, Istanbul, Turkey, ${ }^{2}$ Otago Medical School, \\ University of Otago, Dunedin, New Zealand, ${ }^{3}$ Department of Radiology, Duke University, Durham, NC, United States
}

Fibroblast activation protein (FAP), overexpressed on cancer-associated fibroblasts (CAFs), is a novel target for molecular imaging of various tumors. Recently, the development of several small-molecule FAP inhibitors for radiolabeling with ${ }^{68} \mathrm{Ga}$ has resulted in the emergence of studies evaluating its clinical role in cancer imaging. Preliminary findings have demonstrated that, in contrast to radiotracers taking advantage of cancer-specific targets such as PSMA and DOTATATE, FAPs as a target are the most promising that can compete with ${ }^{18} \mathrm{FDG}$ in terms of widespread indications. They also have the potential to overcome the shortcomings of ${ }^{18} \mathrm{FDG}$, particularly falsepositive uptake due to inflammatory or infectious processes, low sensitivity in certain cancer types, and radiotherapy planning. In addition, the attractive theranostic properties may facilitate the treatment of many refractory cancers. This review summarizes the current FAP variants and related clinical studies, focusing on radiopharmacy, dosimetry, and diagnostic and theranostic applications.

Keywords: PET, cancer-associated fibroblast, fibroblast activation protein, theranostic, 68Ga-FAPI04, FAPI

\section{INTRODUCTION}

Historically, cancer imaging has focused on morphological anatomy, as opposed to molecular imaging, which targets physiological activity in a specific tissue by utilizing modalities that use certain probes to overcome the poorly reflected biology of cancer by anatomical imaging. In this regard, the association between glycolysis and cancer cell metabolism has well been translated into PET imaging in cancer, and ${ }^{18} \mathrm{~F}-\mathrm{FDG}$ PET/CT has revolutionized cancer imaging and gained widespread acceptance for managing various malignancies. More than 40 years of success of ${ }^{18} \mathrm{~F}$ FDG has also led to the successful integration of specific radiotracers such as ${ }^{68} \mathrm{Ga}$-labeled somatostatin analogs and prostate-specific membrane antigens (PSMA) into clinical practice (1) in the last decade, resulting in an exponentially decreasing timeframe for widespread acceptance. Similarly, the recent emergence of radiolabeled fibroblast activation protein (FAP) inhibitors (FAPI) with pan-cancer targeting features hints at relatively rapid adoption. FAPs are overexpressed by cancer-associated fibroblasts (CAFs) found in the tumor stroma of various cancers, and several radiolabeled FAPI variants have already been introduced as promising targets for PET/CT imaging (2-6). The excellent imaging contrast, low activity in normal organs, and theranostic potential are encouraging; however, activated fibroblasts in benign conditions with inflammatory and wound- 
healing processes can also express FAPs. This review summarizes the pathophysiology of FAPs and clinical implications of FAPtargeted PET/CT data in malignant diseases focusing on radiopharmaceuticals and dosimetry. In this regard, a search of PubMed, MEDLINE, and Scopus databases with one or more combinations of the following terms: "FAPI", "FAPI PET", "cancer-associated fibroblast", "fibroblast activation protein", and "fibroblast activation protein inhibitor" was performed. All papers in English were evaluated and were included if they fell within the scope of this review.

\section{PHYSIOLOGY AND PATHOLOGY}

FAP is a type II transmembrane serine protease expressed in activated tumor stroma and inflamed tissues during wound healing (7). Overexpression has been seen in most epithelial cancers, especially in tumors with a high degree of desmoplasia (8). FAP is not overexpressed by tumor cells themselves; it is overexpressed by CAFs that are responsible for tumor growth, aggressiveness, and migration, which consist of a high tumor volume within the tumor stroma (9); thus, a high expression of FAP on CAFs may be considered a factor of aggressiveness of tumor behavior and poor prognostication (10). The tumor microenvironment (TME) plays a crucial role in the survival, proliferation, and spread of tumor cells (11). FAP is overexpressed on the cancer-related fibroblast cell membrane and TME stromal cells. On the other hand, FAP is barely expressed in healthy adult tissues, except uterine stroma, particularly in the proliferative phase, pancreatic alpha cells, human placenta, and some dermal fibroblasts (12). Because of minimal expression in normal tissue, labeled FAP via radiopharmaceuticals is seen as a promising target in diagnosis as well as therapy in oncology (13).

\section{RADIOPHARMACEUTICALS AND DOSIMETRY}

It has been over 30 years since Garin-Chesa et al. proposed the surface glycoprotein of reactive stromal fibroblasts as potential antibody targets in human epithelial cancer (14). Consecutive attempts for imaging FAPs (15) acknowledged the disadvantages and challenges of the initial compounds, leading to the introduction of small-molecule FAP inhibitors with more favorable characteristics, particularly increased selectivity and affinity $(16,17)$. The preliminary human applications using the early FAP inhibitor, namely FAPI02, demonstrated high tumor specificity but declining uptake over time. Consequently, Lindner et al. (18) evaluated a group of novel tracers derived from FAPI02 to improve tumor uptake and retention and accordingly proposed FAPI04 as a more suitable tracer with the potential for theranostic applications. A dosimetry study including 50 patients with various cancers by Giesel et al. also confirmed the higher tumor retention time of ${ }^{68} \mathrm{Ga}-\mathrm{FAPI} 04$ than ${ }^{68} \mathrm{Ga}-\mathrm{FAPI02}$.
The estimated effective doses for ${ }^{68} \mathrm{Ga}-\mathrm{FAPI} 04$ and ${ }^{68} \mathrm{Ga}-\mathrm{FAPI02}$ $\mathrm{PET} / \mathrm{CT}$ were reported as $1.80 \mathrm{E}-2 \mathrm{mSv} / \mathrm{MBq}$ and $1.64 \mathrm{E}-2 \mathrm{mSv} /$ $\mathrm{MBq}$, respectively, which is similar to that of clinically established PET imaging procedures. These values are comparable or lower than the effective dose of $\mathrm{PET} / \mathrm{CT}$ imaging with ${ }^{18}$ F-FDG (1.9E-2 mSv/MBq) (19), ${ }^{68}$ Ga-labeled somatostatin analogs $(2.1 \mathrm{E}-2 \mathrm{mSv} / \mathrm{MBq})(20)$, and ${ }^{68} \mathrm{Ga}-\mathrm{PSMA}$ (1.71E-2-2.3E-2 mSv/MBq) (21).

Further research on FAPI molecules has been conducted to improve the therapeutic efficacy through higher-dose delivery. Higher tumor-to-organ/blood ratios achieved with FAPI21 and FAPI46, as reported by Loktev et al. (3), were promising; however, due to increased uptake of FAPI21 in the oral mucosa, thyroid, and salivary glands, FAPI46 was presumed more favorable. Accordingly, clinical imaging studies with ${ }^{68} \mathrm{Ga}$ FAPI46 in a cohort of 69 patients by Ferdinandus et al. (22) and six patients by Koerber et al. (20) have demonstrated encouraging results. Another novel FAP inhibitor with a different structure based on the squaric acid motif, DOTA.SA.FAPi has also been introduced (23). Human studies also confirmed high target-to-background ratios achieved with colorectal cancer xenograft mouse model in a cohort of 54 patients (24). The mean effective dose equivalent was $1.64 \mathrm{E}-2$ $\mathrm{mSv} / \mathrm{MBq}$, similar to other FAPI PET studies.

Most FAP inhibitors have been labeled using the DOTA derivatives; nevertheless, NOTA chelators have also been studied. A FAP inhibitor, FAPI74, which allows labeling with ${ }^{18} \mathrm{~F}$ and ${ }^{68} \mathrm{Ga}$, has also been studied in a cohort of 10 patients (4). High contrast imaging and low radiation burden using ${ }^{18} \mathrm{~F}$ FAPI74 were reported (effective dose rate of $1.4 \mathrm{E}-2 \mathrm{mSv} /$ $\mathrm{MBq}$ ). Wang et al. (6) also introduced a NOTA-FAPI, $\mathrm{Al}^{18} \mathrm{~F}$ NOTA-FAPI, with comparable affinity with several other FAPI probes. They reported successful imaging of 10 cancer patients and calculated the whole-body effective dose of $1.24 \mathrm{E}-02 \mathrm{mSv} /$ MBq. Another FAPI molecule that allows ${ }^{18} \mathrm{~F}$ labeling is the glycosylated FAP inhibitor ( ${ }^{18}$ FFGlc-FAPI). Toms et al. (25) evaluated ${ }^{18}$ FFGlc-FAPI in the preclinical setting and proposed it as a candidate that can take advantage of extended PET imaging provided by the longer physical half-life of ${ }^{18} \mathrm{~F}$ and higher tumor retention of Glc-FAPI. The only non-PET radiotracer is reported by Linder et al. (23). The authors have studied novel FAPI variants for labeling using the theranostic pair, ${ }^{99 \mathrm{~m}} \mathrm{Tc}$, and ${ }^{188} \mathrm{Re}$. FAPI34 was labeled with ${ }^{99 \mathrm{~m}} \mathrm{Tc}$, and SPECT scans of two patients were comparable with PET imaging with ${ }^{68} \mathrm{Ga}$-FAPI46.

Despite the enthusiasm that FAPI agents have gained in cancer imaging, the experience on targeted radionuclide applications is mainly restricted to a small number of cases. Thus, data on effective dose rates for therapeutic radionuclides is far limited. In the clinical setting, two metastatic breast cancer patients tolerated treatments very well with ${ }^{177} \mathrm{Lu}$ DOTA.SA.FAPi ${ }^{(26)}$ and ${ }^{90} \mathrm{Y}-\mathrm{FAPI} 04^{18}$, and preliminary results indicated that the treatment was safe. Linder et al. (23) and Kratochwil et al. (27) have treated two patients with ${ }^{90} \mathrm{Y}$ FAPI46 and one with ${ }^{153} \mathrm{Sm}$-FAPI46; however, no dosimetric results were reported. Despite the preliminary patient reports on FAP-targeted radionuclide treatments, the data on dosimetry of 
normal organs is still lacking. Recently, Kuyumcu et al. (28) reported estimated radiation-absorbed doses to normal organs using low-dose ${ }^{177} \mathrm{Lu}$-FAPI04. The estimated radiation dose to critical organs was significantly low compared with clinically established targeted radionuclide therapies, particularly ${ }^{177} \mathrm{Lu}-$ DOTATATE and ${ }^{177} \mathrm{Lu}$-PSMA. Bone marrow was the doselimiting organ, and the authors concluded that up to $50 \mathrm{GBq}$ of cumulative activity could be tolerated. These results are expected regarding the high image contrast; however, the relatively short tumor retention time requires dose increase to achieve tumoricidal effects. Therefore, further research is necessary to optimize the therapeutic efficacy and determine the safety of high-dose radionuclide treatments. Baum et al. (29) reported comparable estimated radiation dose to critical organs using ${ }^{177} \mathrm{Lu}$-labeled FAP-2286; however, a higher radiation dose to tumoral lesions was achieved, justifying further investigation.

\section{FIBROBLAST ACTIVATION PROTEIN- TARGETED IMAGING IN ONCOLOGY}

Early clinical trials have evaluated patient groups with various cancers. In 2018, the first PET imaging of FAPs in three patients was reported by Loktev et al. (30) as a proof-of-concept study. Tracer uptake with a high tumor-to-background ratio was noted in breast, lung, and pancreatic cancers. Consequently, Kratochwil et al. (31) from the same team reported the remarkable ${ }^{68} \mathrm{Ga}$-FAPI PET/CT results of 80 cancer patients with 28 different tumor types. The uptake values highly varied between different tumor types as well as individuals. The highest uptake of ${ }^{68} \mathrm{Ga}$-FAPI $\left(\mathrm{SUV}_{\max }>12\right)$ was detected in sarcoma, esophageal, breast, cholangiocarcinoma, and lung cancer patients, while pheochromocytoma, renal cell, differentiated thyroid, and gastric cancers were the lowest $\left(\mathrm{SUV}_{\max }<6\right)$. The low background activity resulted in excellent image contrast despite the intratumoral and interindividual variability even with low tumor activity. In a preliminary study, Giesel et al. (2) evaluated different FAPI variants in a cohort of 50 cancer patients. Similarly, high ${ }^{68} \mathrm{Ga}$-FAPI uptake was observed in esophageal, pancreatic, head and neck, nonsmall cell lung, and colon cancers in contrast to low or no uptake in dedifferentiated thyroid cancer. The authors have demonstrated the first comparative evaluation of ${ }^{68} \mathrm{Ga}$-FAPI PET/CT imaging with ${ }^{18} \mathrm{FDG} \mathrm{PET} / \mathrm{CT}$ in six patients as distinct from other preliminary studies.

Chen et al. (32) compared ${ }^{68}$ Ga-FAPI04 PET/CT with ${ }^{18} \mathrm{FDG}$ PET/CT in a larger cohort of 75 patients. ${ }^{68} \mathrm{Ga}-\mathrm{FAPI04} \mathrm{PET} / \mathrm{CT}$ was superior to ${ }^{18} \mathrm{FDG}$ PET/CT in newly diagnosed 54 patients with 12 tumor types. Similarly, ${ }^{68}$ Ga-FAPI04 was superior in 21 patients with eight cancer types who underwent PET/CT for restaging. The uptake of ${ }^{68} \mathrm{Ga}$-FAPI04 was significantly higher and resulted in high contrast images with the highest uptake in sarcoma, pancreatic, liver, and esophageal cancers. Ten patients with high FAPI04 uptake were negative on ${ }^{18} \mathrm{FDG}$ PET/CT, particularly hepatocellular, gastric, and pancreatic cancers. The sensitivity of ${ }^{68} \mathrm{Ga}-\mathrm{FAPI04} \mathrm{PET} / \mathrm{CT}$ was significantly higher than ${ }^{18}$ FDG in detecting bone, visceral, and lymph node metastases; however, the specificity was lower. Therefore, false positivity also applies to ${ }^{68} \mathrm{Ga}-\mathrm{FAPI} 04$ as a potential diagnostic pitfall and requires careful evaluation. However, ${ }^{68} \mathrm{Ga}-\mathrm{FAPI04}$ PET/CT outperformed ${ }^{18} \mathrm{FDG}$ PET/CT in patients with liver metastasis and peritoneal carcinomatosis. Another comparative study by Chen et al. (33) evaluated 68 cancer patients with inconclusive ${ }^{18}$ FDG-PET/CT findings. Fifty-nine of the patients had histopathologically confirmed malignant disease, and most of the FDG-negative or inconclusive patients, mainly gastric and liver cancers, presented significantly increased 68Ga-FAPI04 uptake. Higher uptake was also noted with peritoneal carcinomatosis, liver, and skeletal metastases. On the other hand, despite high ${ }^{18}$ FDG uptake in the metastatic brain lesions, the tumor-to-background ratio on ${ }^{68} \mathrm{Ga}-\mathrm{FAPI04}$ PET/ CT was higher due to lack of background activity. The authors have highlighted the complementary role of ${ }^{68} \mathrm{Ga}$-FAPI04 imaging in patients with inconclusive ${ }^{18} \mathrm{FDG}$ PET/CT findings.

The encouraging results of studies investigating various cancers have led to the emergence of ${ }^{68} \mathrm{Ga}$-FAPI PET studies in specific cancer types. Head and neck cancers are among the most investigated cancers as a target of FAP-directed PET imaging. In a cohort of 45 patients with nasopharyngeal cancers, ${ }^{68} \mathrm{Ga}$-FAPI04 PET/CT was superior to ${ }^{18} \mathrm{FDG}$ PET/CT in detecting primary tumors, lymph nodes, and metastatic disease, resulting in management changes in $18 \%$ of the patients (34). Qin et al. (35) compared ${ }^{68}$ Ga-FAPI04 with ${ }^{18} \mathrm{FDG} \mathrm{PET} / \mathrm{MR}$ in 15 patients with nasopharyngeal carcinoma. ${ }^{68} \mathrm{Ga}$-FAPI04 uptake in the primary tumors was lower than ${ }^{18}$ FDG uptake, although not statistically different. On the other hand, lower ${ }^{68} \mathrm{Ga}$-FAPI04 uptake in the metastatic lymph nodes was statistically significant; however, ${ }^{68} \mathrm{Ga}-\mathrm{FAPI} 04$ imaging outperformed ${ }^{18} \mathrm{FDG}$ in detecting unknown distant metastases and improved primary tumor delineation for differentiation of skull-base and intracranial invasion. Another study (36) evaluated 14 patients with head and neck cancers and compared ${ }^{68} \mathrm{Ga}-\mathrm{FAPI0} 4$ PET/CT with ${ }^{18}$ FDG-PET/CT for differentiating between healthy and tumor tissue. In a cohort of 12 patients with adenoid cystic carcinomas, Röhrich et al. (37) reported that ${ }^{68} \mathrm{Ga}-\mathrm{FAPI} \mathrm{PET} / \mathrm{CT}$ increased staging accuracy. ${ }^{68} \mathrm{Ga}$-FAPI04 PET/CT was also proposed as a feasible imaging method in 10 patients with oral squamous cell carcinoma by Linz et al. (38), although they did not reach a firm conclusion.

Another cancer group of interest for FAP-targeted imaging is the gastrointestinal malignancies. The advantages of ${ }^{68} \mathrm{Ga}$ FAPI04 over ${ }^{18}$ F-FDG PET/CT in the imaging of esophageal cancer were reported as single-case studies $(39,40)$ and two small cohort studies which investigated the potential of ${ }^{68} \mathrm{Ga}$-FAPI04 $\mathrm{PET} / \mathrm{CT}$ on target volume delineation for radiotherapy planning. Overexpression of FAPs in gastric carcinomas has also been demonstrated (41-43). Quin et al. investigated 20 gastric cancer patients and described the superiority of ${ }^{68} \mathrm{Ga}$-FAPI04 PET/MR over ${ }^{18} \mathrm{~F}$-FDG PET/CT in visualizing the primary tumors and most metastatic lesions (44). Pang et al. (45) evaluated ${ }^{68} \mathrm{Ga}$ FAPI04 PET/CT of 20 patients with gastric carcinoma and reported higher detection rates and mean $\mathrm{SUV}_{\max }$ than $18 \mathrm{FDG}$ 
PET/CT. The authors have also evaluated patients with duodenal $(n=2)$ and colorectal cancers $(n=13)$. The duodenal adenocarcinomas were ${ }^{18}$ FDG negative and demonstrated ${ }^{68} \mathrm{Ga}$-FAPI04 uptake. On the other hand, ${ }^{68} \mathrm{Ga}$-FAPI04 and ${ }^{18}$ FDG PET/CT detected all primary lesions in colorectal cancer patients; however, significantly higher $\mathrm{SUV}_{\max }$ and higher tumor-to-background contrast resulted in more precise tumor delineation. In an investigation into lower gastrointestinal tract tumors, Koerber et al. (20) evaluated the role of FAPI PET/ CT in colon, sigmoid, rectal, and anal cancers. The authors concluded that primary and metastatic tumors could be accurately detected by ${ }^{68} \mathrm{Ga}-\mathrm{FAPI}$ PET/CT changing TNM status and disease management. Peritoneal carcinomatosis patients $(n=46)$ were evaluated by Zhao et al. (46), and the authors reported sensitivity of ${ }^{68} \mathrm{Ga}-\mathrm{FAPI} 04$ PET/CT superior to ${ }^{18}$ F-FDG PET/CT in detecting diffuse or nodular type disease. They also noted that significantly higher tracer uptake was mainly observed in peritoneal carcinomatosis from gastric cancer.

The characteristics of FDG uptake in primary liver malignancies are unpredictable, particularly in hepatocellular carcinoma (HCC) due to factors such as low metabolism and physiological liver activity (47). In a cohort of 17 patients, Shi et al. reported higher ${ }^{68} \mathrm{Ga}$-FAPI04 uptake in malignant liver nodules than in benign nodules (48). The authors have also evaluated hepatocellular carcinoma $(n=14)$ and intrahepatic cholangiocarcinoma $(n=3)$ patients in another study (49) and concluded the superiority of ${ }^{68} \mathrm{Ga}-\mathrm{FAPI} 04 \mathrm{PET} / \mathrm{CT}$ over ${ }^{18} \mathrm{~F}$ FDG PET/CT in the detection of primary hepatic malignancies. Guo et al. (50) confirmed the superiority of ${ }^{68} \mathrm{Ga}$-FAPI04 PET/ CT in 20 patients with hepatocellular carcinoma and 12 patients with intracellular cholangiocarcinoma with a sensitivity equivalent to that of contrast-enhanced CT and MRI. They also reported two patients with benign nodules that were ${ }^{68} \mathrm{Ga}$ FAPI negative and highlighted its potential in differentiating benign from malignant lesions. Similarly, the ability of dynamic ${ }^{68} \mathrm{Ga}$-FAPI04 PET/CT in differentiating HCC from non-HCC lesions has also been demonstrated in a brief report $(51) .{ }^{68} \mathrm{Ga}-$ FAPI04 PET/CT was compared with contrast-enhanced CT in 19 pancreatic ductal adenocarcinoma patients, and ${ }^{68}$ Ga-FAPI04 PET/CT results changed TNM staging in 10 patients. However, the authors have noted challenges of differentiating pancreatitis from adenocarcinoma (52). In another study, Liermann et al. (53) compared ${ }^{68} \mathrm{Ga}$-FAPI04 PET/CT with ceCT in seven recurrent pancreatic patients for radiotherapy planning. However, both studies did not use ${ }^{18} \mathrm{~F}-\mathrm{FDG}$ PET/CT for comparison.

In a study by Komek et al. (54), the authors compared the ${ }^{68} \mathrm{Ga}$-FAPI04 with ${ }^{18}$ F-FDG PET/CT of 20 breast cancer patients and concluded that ${ }^{68} \mathrm{Ga}$-FAPI04 was superior to ${ }^{18} \mathrm{~F}$-FDG in detecting the primary tumor and the metastatic lesions with high sensitivity and tumor-to-background ratio. In a study by Dendl et al. (55), investigating patients with various gynecological malignancies, 14 patients had breast cancer, and the authors have reported strong to moderate FAP expression in the stroma of breast carcinomas. FAP expression in ovarian $(n=9)$, cervical $(n=4)$, endometrial $(n=2)$, and tubal cancers $(n=1)$ in addition to one patient with uterine leiomyosarcoma was also investigated. High tracer uptake and low background activity in gynecological tumors resulted in excellent image contrast compared with ${ }^{18} \mathrm{~F}-\mathrm{FDG}$, and the authors recommended further research on clinical applications.

Koerber et al. (56) evaluated the role of ${ }^{68} \mathrm{Ga}$-FAPI imaging in a cohort of 15 patients diagnosed with various sarcoma subtypes. The excellent tumor-to-background ratio was achieved in primary tumors and metastases, including low-grade sarcomas, where ${ }^{18}$ F-FDG PET/CT has limitations. Accordingly, ${ }^{68} \mathrm{Ga}$ FAPI PET/CT was highlighted as a promising probe with the potential for the theranostic approach. Kessler et al. (57) evaluated 47 patients with bone or soft tissue sarcomas and measured a significant association between tracer uptake and histopathological FAP expression. High sensitivity and PPV of FAPI PET resulted in upstaging in eight (13\%) patients and management change in $13(30 \%)$ patients compared with FDG-PET.

${ }^{18}$ F-FDG PET/CT has a limited role in diagnosing malignant brain tumors and is particularly useful in distinguishing recurrent tumors from radiation necrosis. On the other hand, lack of background activity in FAP-targeted imaging provides high image contrast, and this advantage over FDG PET has been addressed in various reports, particularly for brain metastases. Regarding primary brain tumors, two studies have evaluated FAP-targeted imaging for glioblastomas. Windisch et al. (58) has studied 14 glioblastoma patients in the setting of radiotherapy planning. A diagnostic study by Rohrich et al. (59) in 18 glioma patients evaluated FAP-specific imaging as a promising new tool to differentiate between low-grade and high-grade diseases. In this regard, PET imaging of FAPs may potentially be used as a noninvasive probe for predicting malignant progression of IDHmutant WHO grade II gliomas to grades III and IV over time, which may have severe therapeutic consequences.

${ }^{18}$ F-FDG PET/CT has a well-established impact on highgrade lymphoma management; however, its role in indolent, low-grade disease is controversial. Recently, Jin et al. (60) investigated 11 Hodgkin lymphoma and 62 non-Hodgkin lymphoma patients, and increased radiotracer uptake was observed in Hodgkin lymphoma. Indolent lymphomas showed mild uptake in contrast to aggressive non-Hodgkin lymphomas with high uptake, which resulted in a positive association between the corresponding clinical classification of nonHodgkin lymphomas.

In a recent meta-analysis, Sollini et al. (61) evaluated 23 studies that included 17 oncologic and six non-oncologic articles to evaluate the potential role of ${ }^{68} \mathrm{Ga}$-FAPI imaging. They found that the superiority of ${ }^{68} \mathrm{Ga}$-FAPI over ${ }^{18} \mathrm{~F}$-FDG was observed especially in abdominal cancers in detecting either the primary tumor or the nodal and distant metastases. They demonstrated estimated pooled sensitivity and specificity of patient-based ${ }^{68} \mathrm{Ga}$ FAPI imaging were 0.99 (95\% CI, $0.97-1.00 ; I^{2}=0.00 \% ; p=0.75$ ) and 0.87 (95\% CI, $\left.0.62-1.00 ; I^{2}=0.00 \% ; p=0.51\right)$ with negligible heterogeneity, respectively. On the contrary, the lesion-based analysis revealed high heterogeneity in sensitivity and specificity. 
Meanwhile, pooled sensitivity for the primary tumor and distant metastases was found 1.00 (95\% CI, 0.98-1.00; $I^{2}=0.00 \% ; p=$ 0.51 ) and 0.93 (95\% CI, $0.88-0.97 ; I^{2}=0.00 \% ; p=0.41$ ) with negligible heterogeneity, respectively, whereas pooled sensitivity and specificity of nodal metastases had high heterogeneity $\left(I^{2}=\right.$ $89.18 \%$ and $\left.I^{2}=95.74\right)$. Consequently, FAPI PET was demonstrated as a promising radiopharmaceutical, especially in some malignancies with low FDG uptake in the primary tumor or its metastasis. Table 1 summarizes the studies evaluating FAPtargeted imaging and Figure 1 illustrates intraindividual comparison of ${ }^{18} \mathrm{FDG}$ and ${ }^{68} \mathrm{Ga}$-FAPI04 PET/CT in various cancer entities.

TABLE 1 | Summary of studies evaluating FAP-targeted imaging of various cancer types.

\begin{tabular}{|c|c|c|c|}
\hline Reference & Malignant disease & $n$ & Study outcome \\
\hline Loktev et al. (30) & Various types of cancer & 8 & $\begin{array}{l}\text { FAPI allows rapid and quality imaging and labeling with therapeutic isotopes in tumors with high stromal } \\
\text { content. }\end{array}$ \\
\hline Kratochwil et al. (31) & Various types of cancer & 80 & $\begin{array}{l}\text { The highly selective tumor uptake of FAPI may reveal new applications for noninvasive tumor characterization, } \\
\text { staging imaging, or radioligand therapy. }\end{array}$ \\
\hline Giesel et al. (2) & Various types of cancer & 50 & $\begin{array}{l}\text { FAPI-targeted PET does not require any diet or fasting; it has better image quality than }{ }^{18} \mathrm{~F}-\mathrm{FDG} \text {, and } \\
\text { acquisition can be obtained earlier. }\end{array}$ \\
\hline Chen et al. (32) & Various types of cancer & 75 & $\begin{array}{l}{ }^{68} \mathrm{Ga}-\mathrm{FAPI} \text { PET/CT showed superior diagnostic efficiency compared with 18F-FDG PET/CT, particularly in the } \\
\text { diagnosis of liver metastases, peritoneal carcinomatosis, and brain tumors. }\end{array}$ \\
\hline Chen et al. (33) & Various types of cancer & 68 & $\begin{array}{l}\text { In patients with inconclusive }{ }^{18} \mathrm{~F}-\mathrm{FDG} \text { PET/CT findings, }{ }^{68} \mathrm{Ga}-\mathrm{FAPI} \text { may have a complementary role in } \\
\text { differentiating malignant lesions, locating the primary site of unknown malignancy. }\end{array}$ \\
\hline Zhao et al. (34) & $\begin{array}{l}\text { Nasopharyngeal } \\
\text { carcinoma }\end{array}$ & 45 & $\begin{array}{l}{ }^{68} \mathrm{Ga}-\mathrm{FAPI} \mathrm{PET} / \mathrm{CT} \text { can diagnose primary and metastatic nasopharyngeal carcinoma and supplement MRI for } \\
\text { T staging and radiotherapy planning. }\end{array}$ \\
\hline Qin et al. (35) & $\begin{array}{l}\text { Nasopharyngeal } \\
\text { carcinoma }\end{array}$ & 15 & ${ }^{68} \mathrm{Ga}$-FAPI shows better diagnostic performance than ${ }^{18} \mathrm{~F}-\mathrm{FDG}$ in patients with nasopharyngeal carcinoma. \\
\hline Syed et al. (36) & Head and neck cancer & 14 & $\begin{array}{l}\text { A novel approach of tumor detection, contouring, and targeted radiotherapy of head and neck cancers using } \\
{ }^{68} \text { Ga-FAPI PET. }\end{array}$ \\
\hline Röhrich et al. (37) & Adenoid cystic carcinoma & 12 & $\begin{array}{l}{ }^{68} \mathrm{Ga}-\mathrm{FAPI} \text { PET/CT is a promising imaging modality for adenoid cystic carcinomas, increasing the accuracy of } \\
\text { staging exams and radiotherapy planning volumes compared with conventional CT and MRI. }\end{array}$ \\
\hline Linz et al. (38) & $\begin{array}{l}\text { Oral cavity squamous cell } \\
\text { carcinoma }\end{array}$ & 10 & $\begin{array}{l}\text { Compared with }{ }^{18} \mathrm{~F}-\mathrm{FDG} \text { and cervical MRI, }{ }^{68} \mathrm{Ga}-\mathrm{FAPI} \text { can reduce patient morbidity, minimizing the number of } \\
\text { neck dissections due to false-positive cervical lymph nodes. }\end{array}$ \\
\hline Qin et al. (44) & Gastric carcinomas & 20 & $\begin{array}{l}{ }^{68} \mathrm{Ga}-\mathrm{FAPI} \text { PET/MR showed better diagnostic performance than }{ }^{18} \mathrm{~F}-\mathrm{FDG} \text { PET/CT in visualizing the primary } \\
\text { and metastatic lesions of gastric cancer. }\end{array}$ \\
\hline Pang et al. (45) & $\begin{array}{l}\text { Gastric, duodenal, and } \\
\text { colorectal cancers }\end{array}$ & 35 & $\begin{array}{l}{ }^{68} \mathrm{Ga} \text {-FAPI PET/CT showed superior diagnostic performance. To compare the diagnostic efficacy of } 68 \mathrm{Ga} \\
\text { FAPI PET/CT and }{ }^{18} \text { F-FDG PET/CT in primary and metastatic cancers of the gastrointestinal tract. }\end{array}$ \\
\hline Koerber et al. (20) & $\begin{array}{l}\text { Colon, sigmoid, rectal, } \\
\text { and anal cancers }\end{array}$ & 22 & $\begin{array}{l}{ }^{68} \text { Ga-FAPI PET/CT imaging of lower gastrointestinal tract primary and metastatic tumors resulted in changes } \\
\text { in TNM staging and treatment management. }\end{array}$ \\
\hline Zhao et al. (46) & Peritoneal carcinomatosis & 46 & $\begin{array}{l}{ }^{68} \mathrm{Ga} \text {-FAPI04 PET/CT showed superior diagnostic performance compared with }{ }^{18} \mathrm{~F} \text {-FDG PET/CT to detect } \\
\text { peritoneal carcinomatosis, particularly in gastric cancer. }\end{array}$ \\
\hline Shi et al. (48) & Liver malignancies & 17 & $\begin{array}{l}{ }^{68} \mathrm{Ga}-\mathrm{FAPI} 04 \text { has demonstrated high sensitivity, particularly in the detection of poorly differentiated hepatic } \\
\text { malignancies. }\end{array}$ \\
\hline Shi et al. (49) & Liver malignancies & 20 & ${ }^{68} \mathrm{Ga}-\mathrm{FAPI}$ PET/CT has superior potential for imaging of hepatic tumors compared with ${ }^{18} \mathrm{~F}$-FDG PET/CT. \\
\hline Guo et al. (50) & Liver malignancies & 34 & $\begin{array}{l}\text { The sensitivity of }{ }^{68} \mathrm{Ga}-\mathrm{FAPIO} 4 \mathrm{PET} / \mathrm{CT} \text { in detecting primary and metastatic liver lesions is equivalent to that of } \\
\text { contrast-enhanced CT and MRI and better than }{ }^{18} \mathrm{~F}-\mathrm{FDG} \mathrm{PET} / \mathrm{CT} \text {. }\end{array}$ \\
\hline Geist et al. (51) & Hepatic lesions & 8 & Dynamic ${ }^{68} \mathrm{Ga}-\mathrm{FAPI}$ PET scan allows differentiation between hepatocellular carcinoma and non-HCC lesions \\
\hline Röhrich et al. (52) & $\begin{array}{l}\text { Pancreatic ductal } \\
\text { adenocarcinomas }\end{array}$ & 19 & $\begin{array}{l}{ }^{68} \mathrm{Ga} \text {-FAPI PET/CT allowed restaging in half of the patients with PDAC and the majority of patients with } \\
\text { recurrent disease compared with standard-of-care imaging. }\end{array}$ \\
\hline Liermann et al. (53) & Pancreatic cancer & 7 & $\begin{array}{l}\text { FAPI PET/CT seems to be a superior imaging modality to contrast-enhanced CT, which is the current gold } \\
\text { standard in pancreatic cancer with the potential as a tool for automatic target volume definition before } \\
\text { radiotherapy. }\end{array}$ \\
\hline Kömek et al. (54) & Breast cancer & 20 & $\begin{array}{l}{ }^{68} \mathrm{Ga}-\mathrm{FAPIO} 4 \mathrm{PET} / \mathrm{CT} \text { is superior to } 18 \mathrm{~F}-\mathrm{FDG} \mathrm{PET} / \mathrm{CT} \text { in detecting primary tumors and metastases in breast } \\
\text { cancer patients. }\end{array}$ \\
\hline Dendl et al. (55) & $\begin{array}{l}\text { Gynecological } \\
\text { malignancies }\end{array}$ & 31 & $\begin{array}{l}{ }^{68} \mathrm{Ga} \text { FAPI PET/CT seems to be a more promising imaging modality for staging and follow-up of gynecological } \\
\text { tumors compared with }{ }^{18} \text { F-FDG PET/CT }\end{array}$ \\
\hline Koerber et al. (56) & Several types of sarcoma & 15 & $\begin{array}{l}{ }^{68} \mathrm{Ga}-\mathrm{FAPI} \mathrm{PET} / \mathrm{CT} \text { has a high potential for clinical use in patients diagnosed with sarcoma as a staging probe } \\
\text { and tumor characterization. }\end{array}$ \\
\hline Kessler et al. (57) & $\begin{array}{l}\text { Bone and soft tissue } \\
\text { sarcomas }\end{array}$ & 47 & $\begin{array}{l}\text { There is a correlation between tumoral FAPI uptake intensity and histopathological FAP expression in sarcoma } \\
\text { patients, and FAPI PET has a high sensitivity. }\end{array}$ \\
\hline Windish et al. (58) & Glioblastoma & 14 & For target volume delineation, ${ }^{68} \mathrm{Ga}-\mathrm{FAPI} \mathrm{PET}$ outperformed MRI in detecting gross tumor volumes. \\
\hline Röhrich et al. (59) & Gliomas & 18 & $\begin{array}{l}\text { Using FAP-specific PET imaging may allow a noninvasive distinction between low-grade IDH-mutant and high- } \\
\text { grade gliomas. }\end{array}$ \\
\hline Jin et al. (60) & $\begin{array}{l}\text { Different subtypes of } \\
\text { lymphomas }\end{array}$ & 73 & $\begin{array}{l}{ }^{68} \mathrm{Ga}-\mathrm{FAPI} \text { imaging may be an alternative method for detecting FAP expression in lymphoma lesions and } \\
\text { characterizing lymphoma profiles. }\end{array}$ \\
\hline Sollini et al. (61) & Various types of cancer & 482 & $\begin{array}{l}\text { 68Ga-FAPI PET appears to be a suitable method for the detection of primary lesions and distant metastases } \\
\text { of malignancies that are not particularly suitable for 18F-FDG PET imaging. }\end{array}$ \\
\hline
\end{tabular}




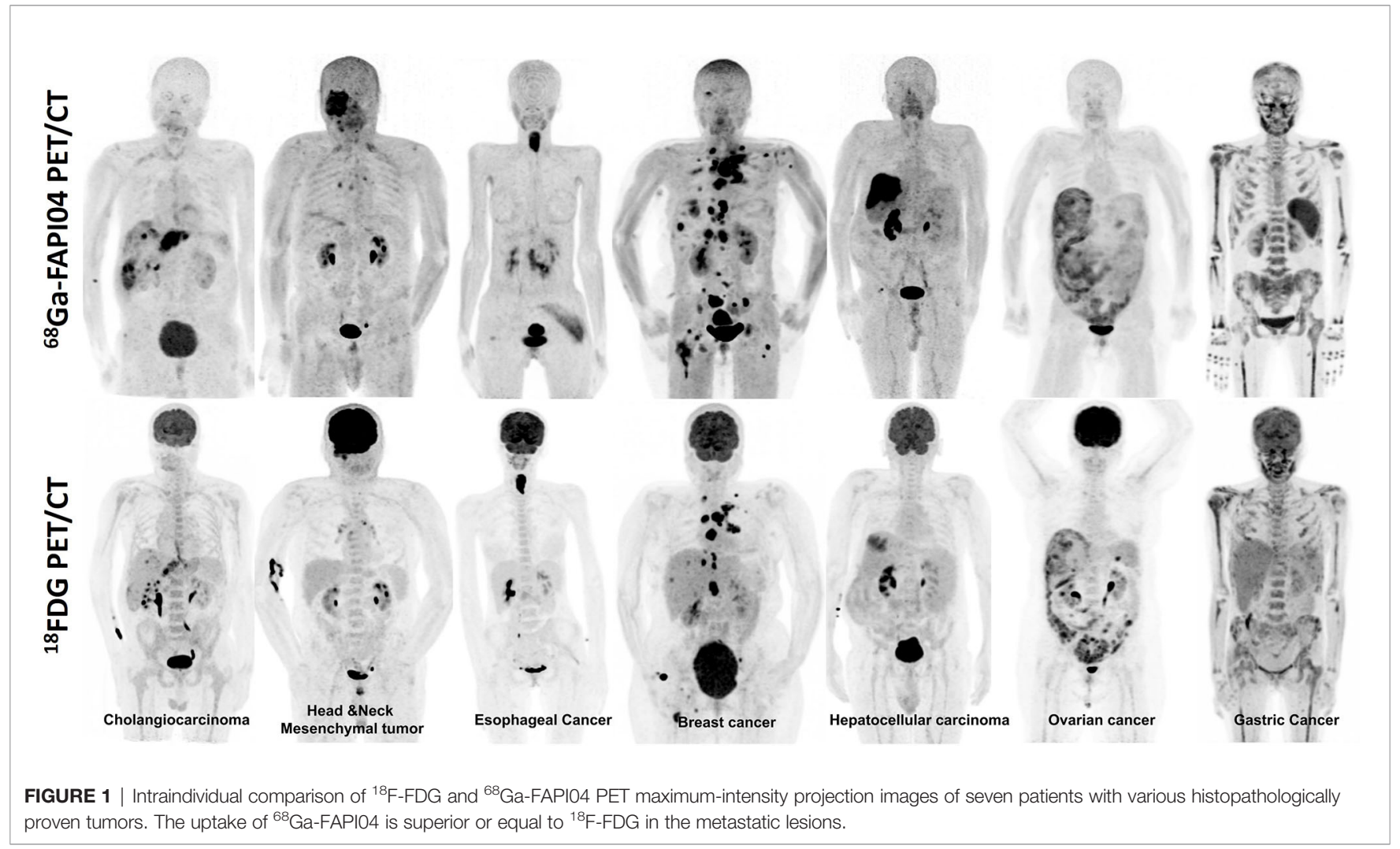

\section{RADIOTHERAPY PLANNING}

Radiotherapy can be used as neoadjuvant or adjuvant therapy in many tumors. Accurate tumor delineation is the most critical part of therapy planning because it directly affects therapy response. Although computed tomography (CT) is the most commonly used modality, numerous studies in literature showed that 18F-FDG PET/CT could be used for delineating metabolic tumor volume to predict tumor response and tumor delineation for radiotherapy planning $(62,63)$. On the other hand, there is no consensus on the optimal method with ${ }^{18} \mathrm{~F}$-FDG PET/CT imaging because of falsepositivity/negativity-like infection/inflammation or masking of the FDG uptake due to tumor location. For this reason, FAPI PET/CT can be a useful alternative radiopharmaceutical to ${ }^{18}$ F-FDG in radiotherapy planning.

Currently, a limited number of articles are available related to radiotherapy planning in the literature. In one of these, Zhao et al. compared the usefulness of ${ }^{68} \mathrm{Ga}$-FAPI with ${ }^{18} \mathrm{~F}$-FDG PET/ CT imaging in evaluating gross tumor volume (GTV) delineation in 21 locally advanced esophageal cancer patients (64). They showed that ${ }^{68} \mathrm{Ga}-\mathrm{FAPI}$ had significantly higher radiotracer uptake than ${ }^{18} \mathrm{~F}$-FDG, especially when the primary tumor was in the middle or lower thoracic esophagus. Moreover, the authors showed that ${ }^{68} \mathrm{Ga}$-FAPI PET/CT had a higher success rate than ${ }^{18} \mathrm{~F}$-FDG $\mathrm{PET} / \mathrm{CT}$ for detecting metastatic lymph nodes. In addition to this study, Ristau et al. also evaluated the impact of primary staging with ${ }^{68} \mathrm{Ga}$-FAPI PET/CT on radiotherapy planning in esophageal cancer patients (65).
They showed that primary tumors demonstrated high FAPI uptake with excellent tumor-to-background ratios that resulted in accurate target volume delineation.

Syed et al. compared GTV between ${ }^{68} \mathrm{Ga}$-FAPI PET/CT and conventional radiologic imaging methods such as contrastenhanced CT and MRI in head and neck cancer in 14 patients (36). Of these, two patients had taken additive radiotherapy after surgical resection for macroscopic residual tumors, whereas the rest of the 12 patients received radiotherapy in the definitive setting with a prior biopsy for histopathological confirmation. They have used four different thresholds (three-, five-, seven-, and tenfold increased uptake) of FAPI uptake in the primary tumor and normal tissue. Eventually, the authors showed that primary tumors had high FAPI avidity, while low background uptakes were shown in healthy tissues in the head and neck region. GTV was found to have significant disparities between all threshold levels of FAPI-GTV to CT-GTV. Also, Röhrich et al. compared the clinical potential of conventional imaging and ${ }^{68} \mathrm{Ga}$-FAPI PET/CT for staging and radiotherapy planning in a total of 12 (seven primary, five recurrent) adenoid cystic carcinoma patients in the head and neck region (37). They demonstrated that ${ }^{68} \mathrm{Ga}$-FAPI PET/CT led to upstaging in two of 12 patients and to the detection of additional metastases in three patients and thus staging was altered in $42 \%$ of patients with ${ }^{68} \mathrm{Ga}-\mathrm{FAPI} \mathrm{PET} / \mathrm{CT}$. Moreover, they showed that when compared with conventional imaging, the accuracy of target volume delineation for radiotherapy improved with FAPI PET. In addition, in a pilot study, 13 glioblastoma patients who were candidates for radiotherapy were evaluated with 
FAPI PET compared with MRI (58). FAP-specific GTV was created using a five-, seven-, and tenfold threshold of increased uptake compared with normal tissue, and MRI-specific GTV was created based on T1-weighted images. They demonstrated that FAP-specific GTV were significantly different from the MRI-GTV for FAP fivefold threshold but not with FAP seven- and tenfold thresholds. FAP-specific PET target volume delineation was not found covered by MRI-GTVs in this study. All of these studies need to be supported by further studies with larger sample sizes.

\section{THERANOSTICS}

FAP-targeted diagnostic imaging has so far shown promising potential for a broad spectrum of cancers. However, taking theranostic properties and low tracer uptake in nontarget organs into account, the possibility of radionuclide treatments of cancers that are currently not in the scope of nuclear medicine is most appealing. The knowledge of theranostic applications using therapeutic radionuclides such as ${ }^{177} \mathrm{Lu},{ }^{90} \mathrm{Y}$, and ${ }^{225} \mathrm{Ac}$ in metastatic neuroendocrine and prostate cancers will likely accelerate new research data on FAP-targeted radionuclide treatments. Still, the therapeutic applications are limited. The first reported FAP-targeted radionuclide treatment using ${ }^{90} \mathrm{Y}$ FAPI04 was administered to a metastatic breast cancer patient by Lindner et al. (18). The posttreatment bremsstrahlung images were in line with ${ }^{68} \mathrm{Ga}$-FAPI04 PET images, and the treatment was well tolerated with no adverse effects observed. A significant reduction in pain medication proved the potential efficacy of the treatment. Dendl et al. (55) reported temporary stable disease in patients with metastatic breast and colon cancer after receiving four cycles of ${ }^{90} \mathrm{Y}$-FAPI04 treatment. Another progressive metastatic breast cancer patient was reported by Ballal et al. (26). The authors used a novel FAP agent based on the squaric acid motif with improved structural features and administered the patient with $3.2 \mathrm{GBq}$ of ${ }^{177} \mathrm{Lu}$-DOTA.SA.FAPi on compassionate grounds. The primary tumor and the metastatic brain lesion received $1.48 \mathrm{E} \mathrm{mGy} / \mathrm{MBq}$ and $3.46 \mathrm{mGy} / \mathrm{MBq}$ absorbed dose. Jokar et al. (66) also reported a metastatic breast carcinoma patient who had failed conventional treatments and received two cycles of ${ }^{177} \mathrm{Lu}-\mathrm{FAPI} 46$. Kratochwil et al. (27) treated a metastatic sarcoma patient using ${ }^{153} \mathrm{Sm}$ and ${ }^{90} \mathrm{Y}$, reaching a cumulative dose of $20 \mathrm{GBq}$ ${ }^{153} \mathrm{Sm}-\mathrm{FAPI} 46$ and $8 \mathrm{GBq}{ }^{90} \mathrm{Y}$-FAPI46 in three cycles. The authors reported 8 months of stable disease, encouraging further studies. So far, two comprehensive studies of FAPtargeting radionuclide treatment have been reported. Baum et al. (29) studied FAP-2286 and administered ${ }^{177}$ Lu-labeled FAP-2286 to 10 patients with pancreas, breast, ovarian, and rectal cancers. Although a treatment response was not achieved, the authors concluded the reasonable toxicity profile with welltolerated adverse effects. Assadi et al. (67) have administered ${ }^{177} \mathrm{Lu}-\mathrm{FAPI} 46$ to 21 patients with various cancers and reported stable disease in 12 of the patients, emphasizing the tolerability and safety of the treatment. The results of both studies agreed that current results warranted further investigation. In summary, the preliminary studies (Table 2 ) have reported low estimated radiation dose to nontarget organs compared with wellestablished radionuclide therapies such as PSMA and DOTATATE. The tumor retention time of FAP inhibitor compounds has evolved since their first introduction; however, dose-escalation studies to achieve tumoricidal effects and optimize the therapeutic efficacy for different tumors require further research.

\section{LIMITATIONS}

Although there is emerging FAP-targeted PET/CT data available for cancer imaging, activated fibroblasts, particularly in tissueremodeling processes, can also express FAPs. As a result, circumstances such as the differentiation of chronic inflammatory or wound-healing processes and malignancy limit the specificity of FAPI PET imaging for certain cancer entities such as pancreatic cancer (52). On the other hand, this allows its use in non-oncological diseases; however, other than the case reports, FAPI PET imaging of nonmalignant conditions has focused on cardiovascular (69-71) and rheumatological (68, 72, 73) diseases. Eventually, clinical adoption of FAPI PET requires understanding the limitations of FAPI PET, its use in

TABLE 2 | Summary of studies evaluating FAP-targeted radionuclide treatments.

\begin{tabular}{|c|c|c|c|c|c|c|c|}
\hline Reference & Malignancy & $n$ & Radiopharmaceutical & Administered dose & Tumor absorbed dose & Cycles & Response \\
\hline Lindner et al. (18) & Breast & 1 & ${ }^{90} \mathrm{Y}-\mathrm{FAPIO} 4$ & $2.9 \mathrm{GBq}$ & $\mathrm{n} / \mathrm{a}$ & 1 & Reduction in pain medication \\
\hline Ballal et al. (26) & Breast & 1 & ${ }^{177}$ Lu-DOTA.SA.FAPi & $3.2 \mathrm{GBq}$ & $\begin{array}{l}1.48 \text { and } 3.46 \text { mGy/ } \\
\mathrm{MBq}\end{array}$ & 1 & $\begin{array}{l}\text { Decrease in the intensity of } \\
\text { headaches. No adverse effects }\end{array}$ \\
\hline Kratochwil et al. (27) & Sarcoma & 1 & $\begin{array}{l}{ }^{153} \mathrm{Sm}-\mathrm{FAPI} 46 \text { and } \\
{ }^{90} \mathrm{Y}-\mathrm{FAPI} 46\end{array}$ & $\begin{array}{l}20 \mathrm{GBq}^{153} \mathrm{Sm}-\text { and } 8 \\
\mathrm{GBq}{ }^{90} \mathrm{Y}-\mathrm{FAPI} 46 \\
\text { (cumulative) }\end{array}$ & $\mathrm{n} / \mathrm{a}$ & 3 & Stable disease for 8 months \\
\hline Baum et al. (29) & Various & 10 & ${ }^{177}$ Lu-FAP-2286 & $5.8 \pm 2.0 \mathrm{GBq}($ mean $)$ & $3 \pm 2.7$ Gy/GBq (mean) & $\begin{array}{c}2 \\
\text { (mean) }\end{array}$ & $\begin{array}{l}\text { PD }(n=10), \operatorname{SD}(n=1) \text {; well } \\
\text { tolerated, no adverse symptoms }\end{array}$ \\
\hline Dendl et al. (55) & $\begin{array}{l}\text { Breast and } \\
\text { colon }\end{array}$ & 1 & ${ }^{90} \mathrm{Y}-\mathrm{FAPI}$ & $\mathrm{n} / \mathrm{a}$ & $\mathrm{n} / \mathrm{a}$ & 4 & PD \\
\hline Jokar et al. (66) & Breast & 1 & ${ }^{177}$ Lu-FAPI46 & 3.7 GBq (per cycle) & $\mathrm{n} / \mathrm{a}$ & 2 & $\mathrm{n} / \mathrm{a}$ \\
\hline Assadi et al. (68) & Various & 21 & ${ }^{177}$ Lu-FAPI46 & 3.7GBq (mean) & $\mathrm{n} / \mathrm{a}$ & $\begin{array}{c}2 \\
\text { (mean) }\end{array}$ & $\mathrm{SD}(n=12)$ and PD $(n=6)$ \\
\hline
\end{tabular}

$S D$, stable disease; $P D$, progressive disease; n/a, not available. 
cancer-specific and non-oncological applications, which can be achieved in the long term.

\section{CONCLUSION}

In diagnostic oncology, targeting increased glucose uptake as a hallmark of cancer-associated metabolic changes by ${ }^{18}$ FDG PET/ $\mathrm{CT}$ is unrivaled. Its capability in detecting metabolic changes even in the absence of anatomical changes has led to high sensitivity; however, increased glycolysis is also common in various nonmalignant diseases and physiological processes, which causes low specificity. Several PET radiotracers have been developed in the last decades; however, they targeted

\section{REFERENCES}

1. Marin JFG, Nunes RF, Coutinho AM, Zaniboni EC, Costa LB, Barbosa FG, et al. Theranostics in Nuclear Medicine: Emerging and Re-Emerging Integrated Imaging and Therapies in the Era of Precision Oncology. RadioGraphics (2020) 40(6):1715-40. doi: 10.1148/rg.2020200021

2. Giesel FL, Kratochwil C, Lindner T, Marschalek MM, Loktev A, Lehnert W, et al. (68)Ga-FAPI PET/CT: Biodistribution and Preliminary Dosimetry Estimate of 2 DOTA-Containing FAP-Targeting Agents in Patients With Various Cancers. J Nucl Med (2019) 60(3):386-92. doi: 10.2967/jnumed.118.215913

3. Loktev A, Lindner T, Burger EM, Altmann A, Giesel F, Kratochwil C, et al. Development of Fibroblast Activation Protein-Targeted Radiotracers With Improved Tumor Retention. J Nucl Med (2019) 60(10):1421-9. doi: 10.2967/ jnumed.118.224469

4. Giesel FL, Adeberg S, Syed M, et al. FAPI-74 PET/CT Using Either (18)F-AlF or Cold-Kit (68)Ga Labeling: Biodistribution, Radiation Dosimetry, and Tumor Delineation in Lung Cancer Patients. J Nucl Med (2021) 62(2):2017. doi: 10.2967/jnumed.120.245084

5. Lindner T, Altmann A, Kramer S, Kleist C, Loktev A, Kratochwil C, et al. Design and Development of (99m)Tc-Labeled FAPI Tracers for SPECT Imaging and (188)Re Therapy. J Nucl Med (2020) 61(10):1507-13. doi: 10.2967/jnumed.119.239731

6. Wang S, Zhou X, Xu X, Ding J, Liu S, Hou X, et al. Clinical Translational Evaluation of $\mathrm{Al}(18) \mathrm{F}-\mathrm{NOTA}-\mathrm{FAPI}$ for Fibroblast Activation ProteinTargeted Tumour Imaging. Eur J Nucl Med Mol Imaging (2021). doi: 10.1007/s00259-021-05470-5

7. Fearon DT. The Carcinoma-Associated Fibroblast Expressing Fibroblast Activation Protein and Escape From Immune Surveillance. Cancer Immunol Res (2014) 2(3):187-93. doi: 10.1158/2326-6066.CIR-14-0002

8. Liu F, Qi L, Liu B, Liu J, Zhang H, Che D, et al. Fibroblast Activation Protein Overexpression and Clinical Implications in Solid Tumors: A Meta-Analysis. PLoS One (2015) 10(3):e0116683. doi: 10.1371/journal.pone.0116683

9. Kalluri R. The Biology and Function of Fibroblasts in Cancer. Nat Rev Cancer (2016) 16(9):582-98. doi: 10.1038/nrc.2016.73

10. Sharma P, Singh SS, Gayana S. Fibroblast Activation Protein Inhibitor PET/ CT: A Promising Molecular Imaging Tool. Clin Nucl Med (2021) 46(3):e141e50. doi: 10.1097/RLU.0000000000003489

11. Balkwill FR, Capasso M, Hagemann T. The Tumor Microenvironment at a Glance. J Cell Sci (2012) 125(Pt 23):5591-6. doi: 10.1242/jcs.116392

12. Šimková A, Bušek P, Šedo A, Konvalinka J. Molecular Recognition of Fibroblast Activation Protein for Diagnostic and Therapeutic Applications. Biochim Biophys Acta Proteins Proteom (2020) 1868(7):140409. doi: 10.1016/ j.bbapap.2020.140409

13. Hamson EJ, Keane FM, Tholen S, Schilling O, Gorrell MD. Understanding Fibroblast Activation Protein (FAP): Substrates, Activities, Expression and Targeting for Cancer Therapy. Proteomics Clin Appl (2014) 8(5-6):454-63. doi: 10.1002/prca.201300095 specific cancer types. FAPIs have the potential to compete with FDG for diagnosis, staging, treatment planning, and therapy response assessment in many human solid tumors. In addition, it has the potential to be a theranostic modality for these tumors and likely transform the therapeutic options available, outside standard treatments, to millions of patients, in the future.

\section{AUTHOR CONTRIBUTIONS}

SK and YS: data collection and extraction and manuscript writing. RS: content planning, study design, and manuscript editing. All authors contributed to the article and approved the submitted version.

14. Garin-Chesa P, Old LJ, Rettig WJ. Cell Surface Glycoprotein of Reactive Stromal Fibroblasts as a Potential Antibody Target in Human Epithelial Cancers. Proc Nat Acad Sci USA (1990) 87(18):7235-9. doi: 10.1073/pnas.87.18.7235

15. Welt S, Divgi CR, Scott AM, Garin-Chesa P, Finn RD, Graham M, et al. Antibody Targeting in Metastatic Colon Cancer: A Phase I Study of Monoclonal Antibody F19 Against a Cell-Surface Protein of Reactive Tumor Stromal Fibroblasts. J Clin Oncol (1994) 12(6):1193-203. doi: 10.1200/JCO.1994.12.6.1193

16. Jansen K, Heirbaut L, Cheng JD, Joossens J, Ryabtsova O, Cos P, et al. Selective Inhibitors of Fibroblast Activation Protein (FAP) With a (4-Quinolinoyl)Glycyl-2-Cyanopyrrolidine Scaffold. ACS Med Chem Lett (2013) 4(5):491-6. doi: $10.1021 / \mathrm{ml} 300410 \mathrm{~d}$

17. Tsai TY, Yeh TK, Chen X, Hsu T, Jao Y-C, Huang C-H, et al. Substituted 4Carboxymethylpyroglutamic Acid Diamides as Potent and Selective Inhibitors of Fibroblast Activation Protein. J Med Chem (2010) 53 (18):6572-83. doi: 10.1021/jm1002556

18. Lindner T, Loktev A, Altmann A, Giesel F, Kratochwil C, Debus J, et al. Development of Quinoline-Based Theranostic Ligands for the Targeting of Fibroblast Activation Protein. J Nucl Med (2018) 59(9):1415-22. doi: 10.2967/jnumed.118.210443

19. Boellaard R, Delgado-Bolton R, Oyen WJ, Giammarile F, Tatsch K, Eschner W, et al. FDG PET/CT: EANM Procedure Guidelines for Tumour Imaging: Version 2.0. Eur J Nucl Med Mol Imaging (2015) 42(2):328-54. doi: 10.1007/ s00259-014-2961-x

20. Koerber SA, Staudinger F, Kratochwil C, Adeberg S, Haefner MF, Ungerechts G, et al. The Role of (68)Ga-FAPI PET/CT for Patients With Malignancies of the Lower Gastrointestinal Tract: First Clinical Experience. J Nucl Med (2020) 61(9):1331-6. doi: 10.2967/jnumed.119.237016

21. Fendler WP, Eiber M, Beheshti M, Bomanji J, Ceci F, Cho S, et al. (68)GaPSMA PET/CT: Joint EANM and SNMMI Procedure Guideline for Prostate Cancer Imaging: Version 1.0. Eur J Nucl Med Mol Imaging (2017) 44(6):101424. doi: $10.1007 / \mathrm{s} 00259-017-3670-\mathrm{Z}$

22. Ferdinandus J, Kessler L, Hirmas N, Trajkovic-Arsic M, Hamacher R, Umutlu L, et al. Equivalent Tumor Detection for Early and Late FAPI-46 PET Acquisition. Eur J Nucl Med Mol Imaging (2021), 1-7. doi: 10.1007/s00259-021-05266-7

23. Moon ES, Elvas F, Vliegen G, De Lombaerde S, Vangestel C, De Bruycker S, et al. Targeting Fibroblast Activation Protein (FAP): Next Generation PET Radiotracers Using Squaramide Coupled Bifunctional DOTA and DATA $(5 \mathrm{~m})$ Chelators. EJNMMI Radiopharm Chem (2020) 5(1):1-20. doi: 10.1186/ s41181-020-00102-z

24. Ballal S, Yadav MP, Moon ES, Kramer VS, Roesch F, Kumari S, et al. Biodistribution, Pharmacokinetics, Dosimetry of [(68)Ga]Ga-DOTA.SA.FAPi, and the Head-to-Head Comparison With [(18)F]F-FDG PET/CT in Patients With Various Cancers. Eur J Nucl Med Mol Imaging (2021) 48(6):1915-31. doi: 10.1007/s00259-020-05132-y

25. Toms J, Kogler J, Maschauer S, Daniel C, Schmidkonz C, Kuwert T, et al. Targeting Fibroblast Activation Protein: Radiosynthesis and Preclinical Evaluation of an (18)F-Labeled FAP Inhibitor. J Nucl Med (2020) 61 (12):1806-13. doi: 10.2967/jnumed.120.242958 
26. Ballal S, Yadav MP, Kramer V, Moon ES, Roesch F, Tripathi M, et al. A Theranostic Approach of [(68)Ga]Ga-DOTA.SA.FAPi PET/CT-Guided [(177)Lu]Lu-DOTA.SA.FAPi Radionuclide Therapy in an End-Stage Breast Cancer Patient: New Frontier in Targeted Radionuclide Therapy. Eur J Nucl Med Mol Imaging (2021) 48(3):942-4. doi: 10.1007/s00259-020-04990-w

27. Kratochwil C, Giesel FL, Rathke H, Fink R, Dendl K, Debus J, et al. [(153)Sm] Samarium-Labeled FAPI-46 Radioligand Therapy in a Patient With Lung Metastases of a Sarcoma. Eur J Nucl Med Mol Imaging (2021), 1-3. doi: 10.1007/s00259-021-05273-8

28. Kuyumcu S, Kovan B, Sanli Y, Buyukkaya F, Simsek DH, Özkan ZG, et al. Safety of Fibroblast Activation Protein-Targeted Radionuclide Therapy by a Low-Dose Dosimetric Approach Using 177lu-Fapi04. Clin Nucl Med (2021) 46(8):641-6. doi: 10.1097/RLU.0000000000003667

29. Baum RP, Schuchardt C, Singh A, Chantadisai M, Robiller FC, Zhang J, et al. Feasibility, Biodistribution and Preliminary Dosimetry in Peptide-Targeted Radionuclide Therapy (PTRT) of Diverse Adenocarcinomas Using (177)LuFAP-2286: First-In-Human Results. J Nucl Med (In Press). doi: 10.2967/ jnumed.120.259192

30. Loktev A, Lindner T, Mier W, Debus J, Altmann A, Jäger D, et al. A TumorImaging Method Targeting Cancer-Associated Fibroblasts. J Nucl Med (2018) 59(9):1423-9. doi: 10.2967/jnumed.118.210435

31. Kratochwil C, Flechsig P, Lindner T, Abderrahim L, Altmann A, Mier W, et al. (68)Ga-FAPI PET/CT: Tracer Uptake in 28 Different Kinds of Cancer. J Nucl Med (2019) 60(6):801-5. doi: 10.2967/jnumed.119.227967

32. Chen H, Pang Y, Wu J, Zhao L, Hao B, Wu J, et al. Comparison of [(68)Ga] Ga-DOTA-FAPI-04 and [(18)F] FDG PET/CT for the Diagnosis of Primary and Metastatic Lesions in Patients With Various Types of Cancer. Eur J Nucl Med Mol Imaging (2020) 47(8):1820-32. doi: 10.1007/s00259-020-04769-Z

33. Chen H, Zhao L, Ruan D, Pang Y, Hao B, Dai Y, et al. Usefulness of [(68)Ga] Ga-DOTA-FAPI-04 PET/CT in Patients Presenting With Inconclusive [(18) F]FDG PET/CT Findings. Eur J Nucl Med Mol Imaging (2021) 48(1):73-86. doi: 10.1007/s00259-020-04940-6

34. Zhao L, Pang Y, Zheng H, Han C, Gu J, Sun L, et al. Clinical Utility of [(68)Ga] Ga-Labeled Fibroblast Activation Protein Inhibitor (FAPI) Positron Emission Tomography/Computed Tomography for Primary Staging and Recurrence Detection in Nasopharyngeal Carcinoma. Eur J Nucl Med Mol Imaging (2021) 1-12. doi: 10.1007/s00259-021-05336-w

35. Qin C, Liu F, Huang J, Ruan W, Liu Q, Gai Y, et al. A Head-to-Head Comparison of (68)Ga-DOTA-FAPI-04 and (18)F-FDG PET/MR in Patients With Nasopharyngeal Carcinoma: A Prospective Study. Eur J Nucl Med Mol Imaging (2021), 1-10. doi: 10.1007/s00259-021-05255-W

36. Syed M, Flechsig P, Liermann J, Windisch P, Staudinger F, Akbaba S, et al. Fibroblast Activation Protein Inhibitor (FAPI) PET for Diagnostics and Advanced Targeted Radiotherapy in Head and Neck Cancers. Eur J Nucl Med Mol Imaging (2020) 47(12):2836-45. doi: 10.1007/s00259-02004859-y

37. Rohrich M, Syed M, Liew DP, Giesel FL, Liermann J, Choyke PL, et al. (68)GaFAPI-PET/CT Improves Diagnostic Staging and Radiotherapy Planning of Adenoid Cystic Carcinomas - Imaging Analysis and Histological Validation. Radiother Oncol (2021) 160:192-201. doi: 10.1016/j.radonc.2021.04.016

38. Linz C, Brands RC, Kertels O, Dierks A, Brumberg J, Gerhard-Hartmann E, et al. Targeting Fibroblast Activation Protein in Newly Diagnosed Squamous Cell Carcinoma of the Oral Cavity - Initial Experience and Comparison to [(18)F]FDG PET/CT and MRI. Eur J Nucl Med Mol Imaging (2021) 1-10. doi: 10.1007/s00259-021-05422-z

39. Zhao L, Chen S, Lin L, Sun L, Wu H, Lin Q, et al. [(68)Ga]Ga-DOTA-FAPI-04 Improves Tumor Staging and Monitors Early Response to Chemoradiotherapy in a Patient With Esophageal Cancer. Eur J Nucl Med Mol Imaging (2020) 47 (13):3188-9. doi: 10.1007/s00259-020-04818-7

40. Liu Q, Shi S, Xu X, Yu X, Song S. The Superiority of [(68)Ga]-FAPI-04 Over [(18)F]FDG PET/CT in Imaging Metastatic Esophageal Squamous Cell Carcinoma. Eur J Nucl Med Mol Imaging (2021) 48(4):1248-9. doi: 10.1007/s00259-020-04997-3

41. Pang Y, Huang H, Fu L, Zhao L, Chen H. 68Ga-FAPI PET/CT Detects Gastric Signet-Ring Cell Carcinoma in a Patient Previously Treated for Prostate Cancer. Clin Nucl Med (2020) 45(8):632-5. doi: 10.1097/RLU.0000000000003099

42. Fan C, Guo W, Su G, Chen B, Chen H. Widespread Metastatic Gastric SignetRing Cell Carcinoma Shown by 68Ga-FAPI PET/CT. Clin Nucl Med (2021) 46 (2):e78-e9. doi: 10.1097/RLU.0000000000003245
43. Lin R, Lin Z, Zhang J, Yao S, Miao W. Increased 68ga-FAPI-04 Uptake in Schmorl Node in a Patient With Gastric Cancer. Clin Nucl Med (2021) 46 (8):700-2. doi: 10.1097/RLU.0000000000003623

44. Qin C, Shao F, Gai Y, Liu Q, Ruan W, Liu F, et al. (68)Ga-DOTA-FAPI-04 PET/MR in the Evaluation of Gastric Carcinomas: Comparison With (18)FFDG PET/CT. J Nucl Med (2021). doi: 10.2967/jnumed.120.258467

45. Pang Y, Zhao L, Luo Z, Hao B, Wu H, Lin Q, et al. Comparison of (68)GaFAPI and (18)F-FDG Uptake in Gastric, Duodenal, and Colorectal Cancers. Radiology (2021) 298(2):393-402. doi: 10.1148/radiol.2020203275

46. Zhao L, Pang Y, Luo Z, Fu K, Yang T, Zhao L, et al. Role of [(68)Ga]GaDOTA-FAPI-04 PET/CT in the Evaluation of Peritoneal Carcinomatosis and Comparison With [(18)F]-FDG PET/CT. Eur J Nucl Med Mol Imaging (2021) 48(6):1944-55. doi: 10.1007/s00259-020-05146-6

47. Kuyumcu S, Has-Simsek D, Iliaz R, Sanli Y, Buyukkaya F, Akyuz F, et al. Evidence of Prostate-Specific Membrane Antigen Expression in Hepatocellular Carcinoma Using 68ga-PSMA PET/CT. Clin Nucl Med (2019) 44(9):702-6. doi: 10.1097/RLU.0000000000002701

48. Shi X, Xing H, Yang X, Li F, Yao S, Zhang H, et al. Fibroblast Imaging of Hepatic Carcinoma With (68)Ga-FAPI-04 PET/CT: A Pilot Study in Patients With Suspected Hepatic Nodules. Eur J Nucl Med Mol Imaging (2021) 48 (1):196-203. doi: 10.1007/s00259-020-04882-z

49. Shi X, Xing H, Yang X, Li F, Yao S, Congwei J, et al. Comparison of PET Imaging of Activated Fibroblasts and (18)F-FDG for Diagnosis of Primary Hepatic Tumours: A Prospective Pilot Study. Eur J Nucl Med Mol Imaging (2021) 48(5):1593-603. doi: 10.1007/s00259-020-05070-9

50. Guo W, Pang Y, Yao L, Zhao L, Fan C, Ke J, et al. Imaging Fibroblast Activation Protein in Liver Cancer: A Single-Center Post Hoc Retrospective Analysis to Compare [(68)Ga]Ga-FAPI-04 PET/CT Versus MRI and [(18)F]FDG PET/CT. Eur J Nucl Med Mol Imaging (2021) 48(5):1604-17. doi: 10.1007/s00259-020-05095-0

51. Geist BK, Xing H, Wang J, Shi X, Zhao H, Hacker M, et al. A Methodological Investigation of Healthy Tissue, Hepatocellular Carcinoma, and Other Lesions With Dynamic (68)Ga-FAPI-04 PET/CT Imaging. EJNMMI Phys (2021) 8 (1):8. doi: 10.1186/s40658-021-00353-y

52. Rohrich M, Naumann P, Giesel FL, Choyke PL, Staudinger F, Wefers A, et al. Impact of (68)Ga-FAPI PET/CT Imaging on the Therapeutic Management of Primary and Recurrent Pancreatic Ductal Adenocarcinomas. J Nucl Med (2021) 62(6):779-86. doi: 10.2967/jnumed.120.253062

53. Liermann J, Syed M, Ben-Josef E, Schubert K, Schlampp I, Sprengel SD, et al. Impact of FAPI-PET/CT on Target Volume Definition in Radiation Therapy of Locally Recurrent Pancreatic Cancer. Cancers (Basel) (2021) 13(4):796. doi: 10.3390/cancers 13040796

54. Komek H, Can C, Guzel Y, Oruç Z, Gündoğan C, Yildirim ÖA, et al. (68)GaFAPI-04 PET/CT, a New Step in Breast Cancer Imaging: A Comparative Pilot Study With the (18)F-FDG PET/CT. Ann Nucl Med (2021) 35(6):744-52. doi: 10.1007/s12149-021-01616-5

55. Dendl K, Koerber SA, Finck R, Mokoala KM, Staudinger F, Schillings L, et al. (68) Ga-FAPI-PET/CT in Patients With Various Gynecological Malignancies. Eur J Nucl Med Mol Imaging (2021) 48(5):4089-100. doi: 10.1007/s00259-021-05378-0

56. Koerber SA, Finck R, Dendl K, Uhl M, Lindner T, Kratochwil C, et al. Novel FAP Ligands Enable Improved Imaging Contrast in Sarcoma Patients Due to FAPI-PET/CT. Eur J Nucl Med Mol Imaging (2021) 48(5):3918-24. doi: 10.1007/s00259-021-05374-4

57. Kessler L, Ferdinandus J, Hirmas N, Bauer S, Dirksen U, Zarrad F, et al. Ga68-FAPI as Diagnostic Tool in Sarcoma: Data From the FAPI-PET Prospective Observational Trial. J Nucl Med 2021:jnumed.121.262096. doi: 10.2967/jnumed.121.262096

58. Windisch P, Rohrich M, Regnery S, Tonndorf-Martini E, Held T, Lang K, et al. Fibroblast Activation Protein (FAP) Specific PET for Advanced Target Volume Delineation in Glioblastoma. Radiother Oncol (2020) 150:159-63. doi: 10.1016/..radonc.2020.06.040

59. Rohrich M, Loktev A, Wefers AK, Altmann A, Paech D, Adeberg S, et al. IDHWildtype Glioblastomas and Grade III/IV IDH-Mutant Gliomas Show Elevated Tracer Uptake in Fibroblast Activation Protein-Specific PET/CT. Eur J Nucl Med Mol Imaging (2019) 46(12):2569-80. doi: 10.1007/s00259-019-04444-y

60. Jin X, Wei M, Wang S, Wang G, Lai Y, Shi Y, et al. Detecting Fibroblast Activation Proteins in Lymphoma Using (68)Ga-FAPI PET/CT. J Nucl Med (2021). doi: 10.2967/jnumed.121.262134 
61. Sollini M, Kirienko M, Gelardi F, Fiz F, Gozzi N, Chiti A. State-Of-the-Art of FAPI-PET Imaging: A Systematic Review and Meta-Analysis. Eur J Nucl Med Mol Imaging (2021). doi: 10.21203/rs.3.rs-543400/v1

62. Gardin I. Methods to Delineate Tumour for Radiotherapy by Fluorodeoxyglucose Positron Emission Tomography. Cancer Radiother (2020) 24(5):418-22. doi: 10.1016/j.canrad.2020.04.008

63. Im HJ, Bradshaw T, Solaiyappan M, Cho SY. Current Methods to Define Metabolic Tumor Volume in Positron Emission Tomography: Which One is Better? Nucl Med Mol Imaging (2018) 52(1):5-15. doi: 10.1007/s13139-017-0493-6

64. Zhao L, Chen S, Chen S, Pang Y, Dai Y, Hu S, et al. (68)Ga-Fibroblast Activation Protein Inhibitor PET/CT on Gross Tumour Volume Delineation for Radiotherapy Planning of Oesophageal Cancer. Radiother Oncol (2021) 158:55-61. doi: 10.1016/j.radonc.2021.02.015

65. Ristau J, Giesel FL, Haefner MF, Staudinger F, Lindner T, Merkel A, et al. Impact of Primary Staging With Fibroblast Activation Protein Specific Enzyme Inhibitor (FAPI)-PET/CT on Radio-Oncologic Treatment Planning of Patients With Esophageal Cancer. Mol Imaging Biol (2020) 22(6):1495-500. doi: 10.1007/s11307-020-01548-y

66. Jokar N, Velikyan I, Ahmadzadehfar H, Rekabpour SJ, Jafari E, Ting HH, et al. Theranostic Approach in Breast Cancer: A Treasured Tailor for Future Oncology. Clin Nucl Med (2021) 46(8):e410-e20.

67. Assadi M, Rekabpour SJ, Jafari E, Divband G, Nikkholgh B, Amini H, et al. Feasibility and Therapeutic Potential of 177Lu-Fibroblast Activation Protein Inhibitor-46 for Patients With Relapsed or Refractory Cancers: A Preliminary Study. Clin Nucl Med (2021) 46(11):e523-30. doi: 10.1097/ RLU.0000000000003810

68. Schmidkonz C, Rauber S, Atzinger A, Katus HA, Haberkorn U, Leuschner F, et al. Disentangling Inflammatory From Fibrotic Disease Activity by Fibroblast Activation Protein Imaging. Ann Rheum Dis (2020) 79(11):148591. doi: 10.1136/annrheumdis-2020-217408

69. Finke D, Heckmann MB, Herpel E, Katus HA, Haberkorn U, Leuschner F, et al. Early Detection of Checkpoint Inhibitor-Associated Myocarditis Using 68ga-FAPI PET/CT. Front Cardiovasc Med (2021) 8(54). doi: 10.3389/ fcrm.2021.614997
70. Heckmann MB, Reinhardt F, Finke D, Nekolla S, Kessler L, Ferdinandus J, et al. Relationship Between Cardiac Fibroblast Activation Protein Activity by Positron Emission Tomography and Cardiovascular Disease. Circ Cardiovasc Imaging (2020) 13(9):e010628. doi: 10.1161/CIRCIMAGING.120.010628

71. Siebermair J, Köhler MI, Kupusovic J, Tascilar K, Müller A-T, Atzinger A, et al. Cardiac Fibroblast Activation Detected by Ga-68 FAPI PET Imaging as a Potential Novel Biomarker of Cardiac Injury/Remodeling. J Nucl Cardiol (2021) 28(3):812-21. doi: 10.1007/s12350-020-02307-w

72. Bergmann C, Distler JHW, Treutlein C, Peng L, Zhang W, Li F. 68Ga-FAPI04 PET-CT for Molecular Assessment of Fibroblast Activation and Risk Evaluation in Systemic Sclerosis-Associated Interstitial Lung Disease: A Single-Centre, Pilot Study. Lancet Rheumatol (2021) 3(3):e185-94. doi: 10.1016/S2665-9913(20)30421-5

73. Luo Y, Pan Q, Yang H, Peng L, Zhang W, Li F. Fibroblast Activation ProteinTargeted PET/CT With (68)Ga-FAPI for Imaging IgG4-Related Disease: Comparison to (18)F-FDG PET/Ct. J Nucl Med (2021) 62(2):266-71. doi: $10.2967 /$ jnumed.120.244723

Conflict of Interest: The authors declare that the research was conducted in the absence of any commercial or financial relationships that could be construed as a potential conflict of interest.

Publisher's Note: All claims expressed in this article are solely those of the authors and do not necessarily represent those of their affiliated organizations, or those of the publisher, the editors and the reviewers. Any product that may be evaluated in this article, or claim that may be made by its manufacturer, is not guaranteed or endorsed by the publisher.

Copyright (c) 2021 Kuyumcu, Sanli and Subramaniam. This is an open-access article distributed under the terms of the Creative Commons Attribution License (CC BY). The use, distribution or reproduction in other forums is permitted, provided the original author(s) and the copyright owner(s) are credited and that the original publication in this journal is cited, in accordance with accepted academic practice. No use, distribution or reproduction is permitted which does not comply with these terms. 